\title{
No Superior Interesse da Criança: Os Contributos da Pedopsiquiatria
}

\section{In the Child's Best Interest: The Contribution of Child and Adolescent Psychiatry}

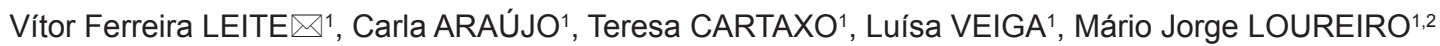
Acta Med Port 2017 Oct;30(10):675-682 - https://doi.org/10.20344/amp.8579

\begin{abstract}
RESUMO
Introdução: A atividade médico-legal, no âmbito da Pedopsiquiatria, consiste numa avaliação por solicitação dos Tribunais, para os assessorar no exercício da Justiça da família / da criança.

Material e Métodos: Estudo retrospetivo, que englobou 233 pedidos de exames periciais e informações clínicas de dois pedopsiquiatras do Serviço de Pedopsiquiatria do Hospital Pediátrico do Centro Hospitalar e Universitário de Coimbra, entre 1998 - 2012.

Resultados: Foram analisados aspetos biográficos, psicopatologia subjacente e contexto sociofamiliar. Foram avaliados também os tempos de resposta nos diferentes momentos do processo, a proveniência e a natureza dos pedidos, bem como o tipo de processo que Ihes deu origem. Os autores identificaram, para cada caso, os profissionais envolvidos no processo e a eventual necessidade de comparência em Tribunal. Perante a existência de quesitos, avaliaram a capacidade de resposta aos mesmos, as dificuldades periciais e respetivas soluções encontradas, bem como a existência ou não de recomendações.

Discussão: Os resultados obtidos foram ao encontro da literatura e experiência clínica relativamente aos dados demográficos e psicopatologia. Quanto às principais dificuldades sentidas, identificaram-se diversos aspetos passíveis de aperfeiçoamento, por ambas as partes, com vista a uma melhor articulação entre a Saúde e a Justiça.

Conclusão: Com este trabalho foi possível refletir acerca da atividade forense dos autores, visando facilitar a articulação da Pedopsiquiatria com os Tribunais, em prol do verdadeiro superior interesse das crianças/adolescentes e suas famílias.

Palavras-chave: Defesa da Criança e do Adolescente; Pedopsiquiatria; Portugal; Prova Pericial; Psiquiatria Forense
\end{abstract}

\section{ABSTRACT}

Introduction: Child and Adolescent Forensic Psychiatry involves a multidisciplinary assessment at the courts' requested to assist them in the process of justice delivery.

Material and Methods: Retrospective study which included 233 forensic requests to two child and adolescent psychiatrists from Coimbra's HP-CHUC Child and Adolescent Psychiatry Department between 1998 and 2012.

Results: Biographic, psychopathology, social and family aspects were analyzed. The response time throughout the process, the origin and nature of the request's and the type of process which originated the request were also assessed. The authors identified the involved professionals and whether they needed to go to court. When there were questions, they evaluated the capacity to answer them, the forensic difficulties and solutions found, and the presence of recommendations.

Discussion: The obtained results met the clinical experience and literature regarding demography and psychopathology. As for the difficulties, there were a number of aspects which could be improved by both parts, aiming to ameliorate the articulation between Health and Justice.

Conclusion: With this study it was possible to reflect on the authors forensic practice, in order to develop a closer partnership with the courts to promote the real 'best interests' of children/adolescents and their families.

Keywords: Child Advocacy; Child Psychiatry; Expert Testimony; Forensic Psychiatry; Portugal

\section{INTRODUÇÃO}

Os profissionais que trabalham em Psiquiatria da Infância e da Adolescência são frequentemente confrontados com diversas solicitações dos Tribunais, tais como pedidos de informações clínicas, notificações para idas a Tribunal ou realização de perícias médico-legais. Os autores propuseram-se fazer uma breve revisão do trabalho desenvolvido nesta área, com vista a um contributo mais profícuo com a Justiça.

Em teoria, qualquer médico especialista constitui um perito e pode, pela sua competência específica numa dada área, ser convocado para exprimir um parecer técnico sobre os factos e circunstâncias submetidos a exame (Artigo $467^{\circ}$ do Novo Código de Processo Civil). ${ }^{1}$ O perito obedecerá a um leque de exigências beneficiando, no entanto, da possibilidade de uma escusa fundamentada em alguns impedimentos previstos na lei, em consonância com os Artigos $469^{\circ}$ e $470^{\circ}$ do Novo Código de Processo Civil. ${ }^{1}$

Incumbido por Lei, o perito coloca a Medicina ao serviço do Direito, movido pelo esclarecimento e enquadramento legal. Assume uma nova vertente enquanto agente público, comprometido com o Estado, com a Justiça e com o dever de Cidadania importando adequada e permanente familiarização com a literatura científica médica e jurídica. ${ }^{2}$

Nesta interface da Pedopsiquiatria com o Direito, cruzam-se diferentes linguagens, objetivos e metodologias, que há que reconhecer e conciliar com vista a obter, se não uma resposta perfeita, uma solução o menos danosa possível para as crianças, jovens e suas famílias. ${ }^{3}$

\footnotetext{
1. Serviço de Pedopsiquiatria. Hospital Pediátrico. Centro Hospitalar e Universitário de Coimbra. Coimbra. Portugal.

2. Department of Child and Adolescent Psychiatry. University Hospital Waterford. Waterford. Ireland.

$\triangle$ Autor correspondente: Vítor Ferreira Leite. vbruno.pedopsiq@gmail.com

Recebido: 17 de dezembro de 2016 - Aceite: 15 de maio de 2017 | Copyright $\odot$ Ordem dos Médicos 2017
} 
O papel pericial implica um espírito aberto e crítico, validado por uma revisão entre pares, que visa representar os interesses da criança/jovem, culminando na elaboração de um relatório com resposta aos quesitos colocados. ${ }^{4}$

A exigência neste papel implica uma especialização teórica e prática, com conhecimentos sólidos acerca do desenvolvimento infanto-juvenil e o impacto das adversidades neste, tendo em conta a influência da família, o conhecimento da psicopatologia, a apresentação forense das doenças mentais e todo um enquadramento legal nomeadamente em matérias de Promoção e Proteção, Medidas Tutelares Educativas, Consentimento Informado, Adoção e Internamento Compulsivo. Implica um treino especializado na avaliação, em diferentes contextos e ambientes, conhecimento de abordagens terapêuticas integradas e perspetiva de programas de cuidados..$^{2,5}$

No papel clínico, o médico procura realizar um diagnóstico e intervenção, fazendo uso da relação médico-doente e de valores como a confiança e a confidencialidade como armas terapêuticas. ${ }^{2,6}$ No papel de perito, o tratamento e o acompanhamento clínico não fazem parte das suas funções, muito embora estejam na linha de crítica do perito. ${ }^{2}$

Desta forma, cabe ao perito elucidar as instituições forenses acerca de assuntos que pela sua natureza não cabem no foro judicial, razão pela qual o perito designado não pode ser o terapeuta da criança ou jovem, desde logo porque a análise terapêutica tem exigências, nomeadamente a proximidade com o menor, que impedem ter o distanciamento exigido para a realização da perícia. $^{7}$

Esta dualidade entre o terapeuta/perito pode suscitar inevitáveis confusões, que importa explanar devidamente junto das famílias, nomeadamente em relação à inexistência de confidencialidade, nos casos solicitados pela autoridade judicial, tornando clara a distinção entre uma consulta médica e uma perícia. ${ }^{7}$ Também aquando da disponibilização de informações para o Tribunal, por solicitação das famílias, nomeadamente em questões de incumprimento das responsabilidades parentais, importa uma adequada clarificação de papéis, sob risco de interpretações erróneas de parcialidade.

A convocatória do psiquiatra da infância e da adolescência para envolvimento forense poderá investi-lo na condição de testemunha profissional, para se pronunciar no âmbito de um acompanhamento clínico, ou de testemunha pericial, enquanto profissional que realizou uma perícia por designação do Instituto Nacional de Medicina Legal e Ciências Forenses (INMLCF). ${ }^{8}$

Quando solicitado a partilhar informações e opiniões relativas a doentes por si acompanhados, levantam-se muitas vezes questões éticas e de sigilo médico. Há que analisar criteriosamente que informação disponibilizar, ponderando riscos/benefícios pelas eventuais repercussões na intervenção terapêutica, para a qual a relação de confiança é fundamental. , $^{, 7}$

Esta forma de envolvimento contrasta com a providenciada por um Pedopsiquiatra que não conheça o caso clínico, intervindo aí enquanto testemunha pericial. Quando solicita uma perícia pedopsiquiátrica, o Tribunal está interessado numa visão formalmente distanciada do caso em questão, podendo pretender obter uma segunda opinião, ou aceder a conhecimentos específicos da Pedopsiquiatria. ${ }^{5}$

A atividade médico-legal, no âmbito da Psiquiatria da Infância e da Adolescência, solicitada aos Serviços de Saúde, implica frequentemente uma avaliação pericial multidisciplinar, necessitando de uma adequada articulação com a Psiquiatria Geral, Pediatria, Psicologia e o Serviço Social. ${ }^{2}$

Os motivos de pedido de perícia são vastos, incluindo casos de delinquência/crime (processos tutelares educativos), suspeitas de maus tratos (negligência e/ou abuso físico ou sexual), decisões relativas a aspetos de regulação das responsabilidades parentais e/ou de colocação residencial (familiar, institucional, regime de visitas e contactos), avaliação da relação cuidadores-criança (vinculação e competências parentais), situações de absentismo escolar, despiste de psicopatologia, consentimento para tratamento (internamento compulsivo ou tratamento compulsivo em ambulatório), avaliação do valor do testemunho ou disputa de compensação/indemnização por dano (p. ex.: casos de stress pós-traumático após acidentes). ${ }^{4,8}$

O trabalho forense não constitui uma avaliação psiquiátrica 'clássica' com os referidos objetivos diagnósticos e terapêuticos, mas configura um procedimento técnico rigoroso, assente em metodologias específicas. ${ }^{5} \mathrm{O}$ laudo pericial é uma forma de fundamento científico para esclarecimento e orientação em situações de dúvida e/ou conflito, daí que a avaliação pericial obrigue a uma avaliação clínica pedopsiquiátrica tão completa quanto possível. A informação colhida poderá ser complementada por meios auxiliares de diagnóstico, pelo depoimento de outros significativos ou relatórios fornecidos por diferentes profissionais e consubstanciada por literatura científica de referência ${ }^{9}$ (Fig. 1).

Embora não exista um modelo formalmente validado para a elaboração do relatório, a avaliação forense deverá contemplar a identificação, condições do exame, histórico e antecedentes pessoais e familiares, exame clínico/mental do menor, eventuais exames complementares, diagnóstico, conclusões médico-legais com resposta aos quesitos. ${ }^{4}$

O relatório deve ser conciso, mas tão completo quanto possível, compatível com o solicitado, redigido numa linguagem compreensível, em papel timbrado, paginado e assinado.

Face à experiência já adquirida, os autores propuseram-se refletir acerca do trabalho forense, recorrendo à análise e tratamento da informação arquivada, visando desta forma poder contribuir, para que se faça cada vez mais e melhor na articulação entre a Saúde e a Justiça.

\section{MATERIAL E MÉTODOS \\ Descrição do estudo}

Foi realizado um estudo retrospetivo, referente a todos os pedidos de exames periciais e informações clínicas de dois pedopsiquiatras do Serviço de Pedopsiquiatria do Hospital Pediátrico do Centro Hospitalar e Universitário de 


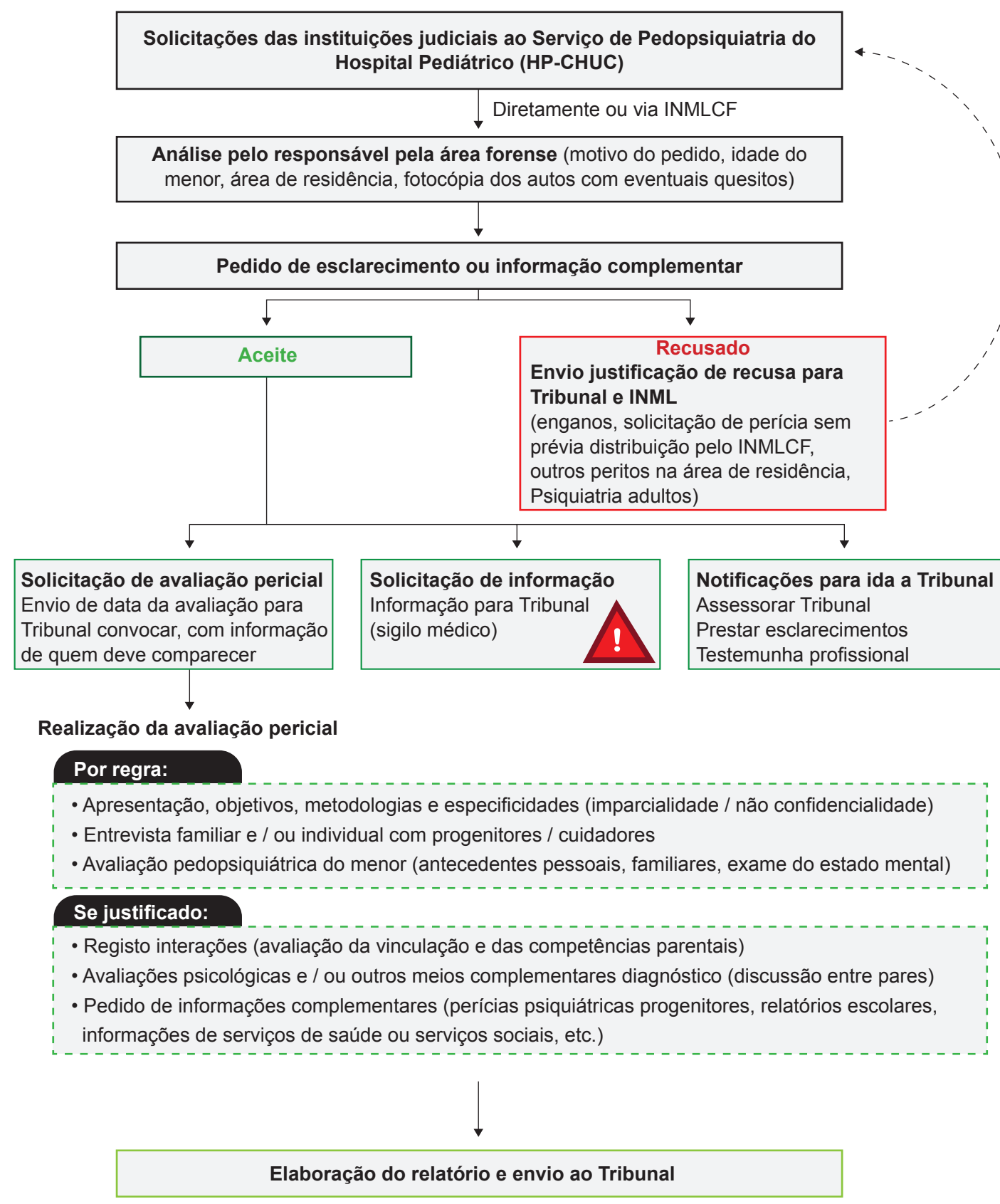

Figura 1 - Fluxograma

Coimbra (HP-CHUC), efetuados num período de 15 anos, entre 1998 e 2012.

Analisaram-se os pedidos das diferentes instituições judiciais, do INMLCF e dos relatórios médico-legais e informações clínicas elaboradas pelos mesmos. Foram recolhidas informações referentes a características clínicas, judiciais e sociodemográficas e, posteriormente, armazenadas numa base de dados do Microsoft Access ${ }^{\circledR}$.

\section{População e elementos estudados}

O estudo englobou 233 solicitações referentes a crianças, adolescentes e jovens adultos com idades compreendidas entre 0 e 25 anos.

Os dois tipos de pedido (perícia médico-legal ou infor- mação clínica), foram revistos em conjunto. Foram analisados aspetos biográficos, caraterizando a população alvo relativamente à idade, sexo, residência, escolaridade, psicopatologia subjacente e contexto sociofamiliar. Foram avaliados também os tempos de resposta nos diferentes momentos do processo, a proveniência e a natureza dos pedidos, bem como o tipo de processo que Ihes deu origem.

Os autores identificaram, para cada caso, os profissionais envolvidos no processo (pedopsiquiatras, internos da especialidade, psicólogos e assistentes sociais) e a eventual necessidade de comparência em Tribunal. Perante a existência de quesitos, avaliaram a capacidade de resposta aos mesmos, as dificuldades periciais e respetivas 
soluções encontradas, bem como a existência ou não de recomendações.

\section{Tratamento de dados}

Para a análise dos dados foi utilizada a versão 20.0 do programa estatístico IBM ${ }^{\circledR}$ SPSS $^{\circledR}$ Statistics (Statistical Package for Social Sciences).

Foi efetuada análise estatística inferencial e descritiva, sendo que esta última incluiu análise de frequências, mediana, valor mínimo e máximo, desvio-padrão, erro-padrão e percentis $(25,50$ e 75$)$.

A análise das variáveis como idade, escolaridade e género foram calculadas recorrendo ao teste de MannWhitney para amostras independentes. As diferenças entre os tempos Tribunal-INMLCF, INMLCF-Serviço de Pedopsiquiatria, dentro do serviço de Pedopsiquiatria (desde a entrada do pedido até à primeira entrevista) e tempo decorrido entre a realização da primeira avaliação e elaboração de relatório, para o grupo geral e para o subgrupo das perícias médico-legais foram calculadas recorrendo ao teste de Friedman para amostras emparelhadas e, no caso das informações clínicas, foi aplicado o teste de Wilcoxon para amostras emparelhadas. As diferenças entre as restantes variáveis em estudo foram calculadas recorrendo ao teste de Kruskal-Wallis para amostras independentes. Para avaliar a relação entre o ano do pedido do Tribunal e os tipos de processo e tipo de solicitação, foi aplicado o teste do qui-quadrado de Pearson. Valores de $p$ inferiores a 0,05 foram admitidos como estatisticamente significativos, considerando um intervalo de confiança de 95\%.

\section{RESULTADOS}

A amostra era constituída maioritariamente por indivíduos do sexo masculino $(59,23 \%)$, com uma média de idades de 10,11 $\pm 4,73$ anos. A separação por idade e género não se mostrou estatisticamente significativa.

No que toca aos detalhes processuais, a grande maioria dos pedidos tinha origem no Tribunal Judicial $(n=144)$, seguido do Ministério Público $(n=42)$ e do Tribunal de Família e Menores $(n=40)$, essencialmente do distrito de Coimbra $(n=82)$, seguido do distrito de Leiria $(n=38)$. Das 233 solicitações, os tipos de processos que levaram à solicitação de intervenção pedopsiquiátrica foram essencialmente processos de regulação das responsabilidades parentais $(n=62)$, inquéritos $(n=62)$ e os processos de promoção e proteção $(n=56)$, sendo os principais motivos subjacentes ao processo a suspeita de abuso sexual ( $n=$ 72 ) e outros maus-tratos $(n=51)$. Apesar da variação ao longo dos anos, como se pode constatar na Fig. 2, manteve-se um predomínio relativamente constante dos tipos de processos supracitados. Verificou-se também relação estatisticamente significativa $(p=0,036)$ entre o tipo de processo e o número de entrevistas necessárias para relatório.

$\mathrm{Na}$ maioria dos casos foi solicitado exame pericial $(74,68 \%)$ contudo, foram encontradas diferenças estatisticamente significativas $(p<0,001)$ entre o tipo de pedido e a instituição judicial, verificando-se que o Tribunal de Família e Menores pede informações clínicas com mais frequência que os restantes. Numa amostra de 16 pedidos de informação clínica, o tempo médio de resposta foi de 128,56 dias.

Na Fig. 3 é possível perceber a evolução do tipo de soli-

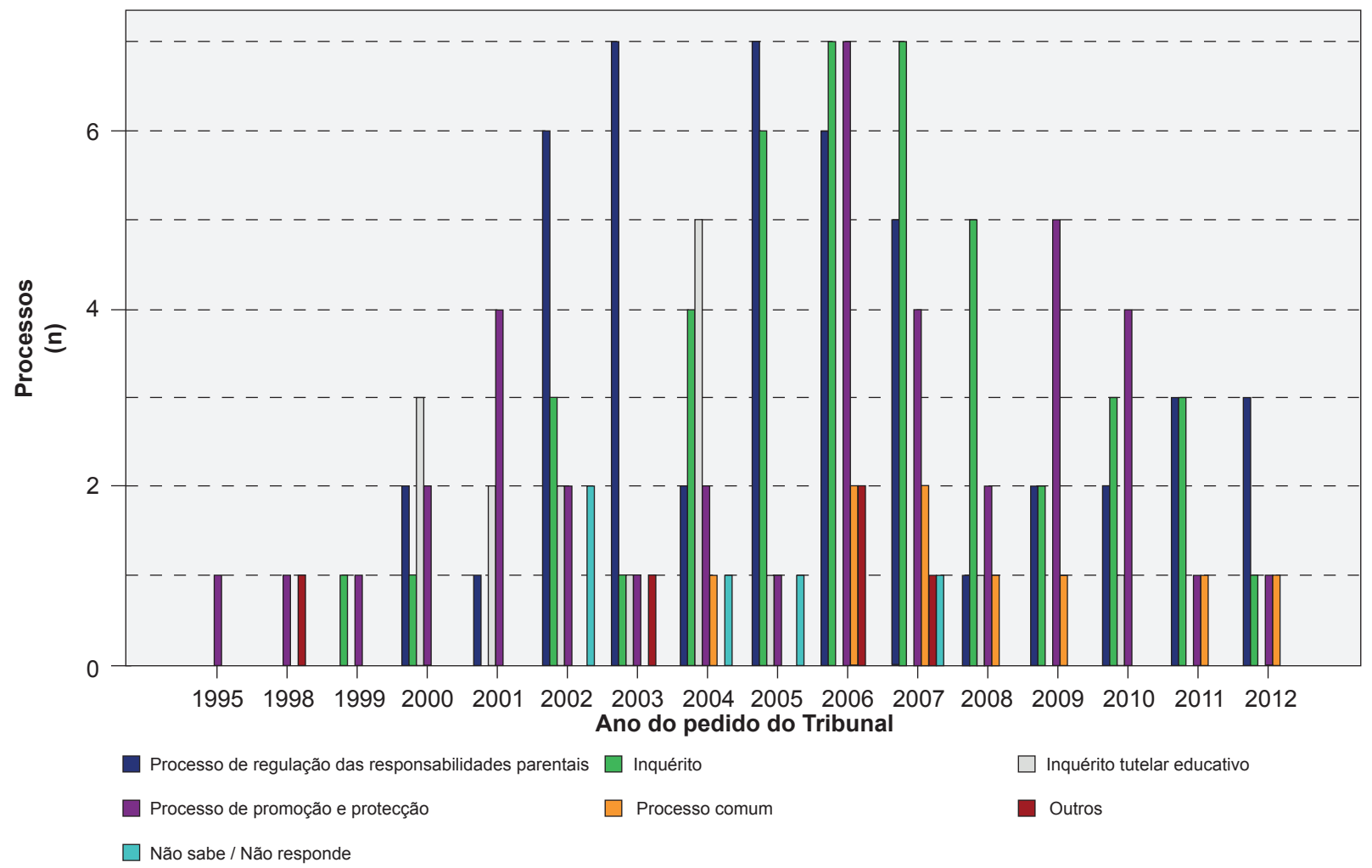

Figura 2 - Tipo de processo que levou à solicitação de intervenção pedopsiquiátrica 
citações ao longo dos anos em estudo, constatando-se um pico de pedidos de perícias em 2006 e sobressaindo uma clara diminuição de ambos os tipos de solicitações judiciais, sobretudo a partir de 2007, com aumento de pedidos de informação em 2007 e 2011.

A comparência do perito no Tribunal foi solicitada em 40 situações dos processos, incluindo como testemunha profissional, perito para prestar esclarecimentos do relatório ou apenas como técnico que vai auxiliar no interrogatório das crianças, e foram encontradas diferenças estatisticamente significativas $(p=0,008)$ entre o número de comparências no Tribunal e o tipo de Tribunal que fez o pedido, sendo superior no caso do Tribunal Judicial.

Verificou-se a existência de quesitos em 53,65\% dos casos, mas em apenas $37,34 \%$ dos casos era possível responder cabalmente aos mesmos através da avaliação pericial, tendo o perito fornecido recomendações para a Instituição Judicial em $66,52 \%$ dos casos. Quando não existiam quesitos verificava-se, com significado estatístico $(p<0,001)$, que o número de entrevistas necessárias para a elaboração do relatório era superior, sendo que a média, independentemente da existência ou não de quesitos, era de quatro entrevistas.

Foram encontradas diferenças estatisticamente significativas $(p<0,001)$ entre os tempos de resposta das várias instituições envolvidas: Tribunal - INMLCF, INMLCF - serviço de Pedopsiquiatria, dentro do serviço de Pedopsiquiatria (desde a data de receção pelo perito até à data do agendamento da perícia) e tempo decorrido entre a realização da primeira entrevista da perícia e a elaboração de relatório, sendo o maior tempo o da realização da perícia (média 65 $\pm 6,503$ dias) - Tabela 1 .

Relativamente aos profissionais envolvidos, em 18,45\% incluiu apenas um pedopsiquiatra e em $81,55 \%$ a colaboração adicional de outros técnicos, como internos da especialidade, psicólogos e assistentes sociais. Participou pelo menos um formando, interno de Pedopsiquiatria em cerca de $50 \%$ dos casos.

Foi possível confirmar que a avaliação pericial foi relevante em $11,16 \%$ dos casos, sendo que na restante maioria

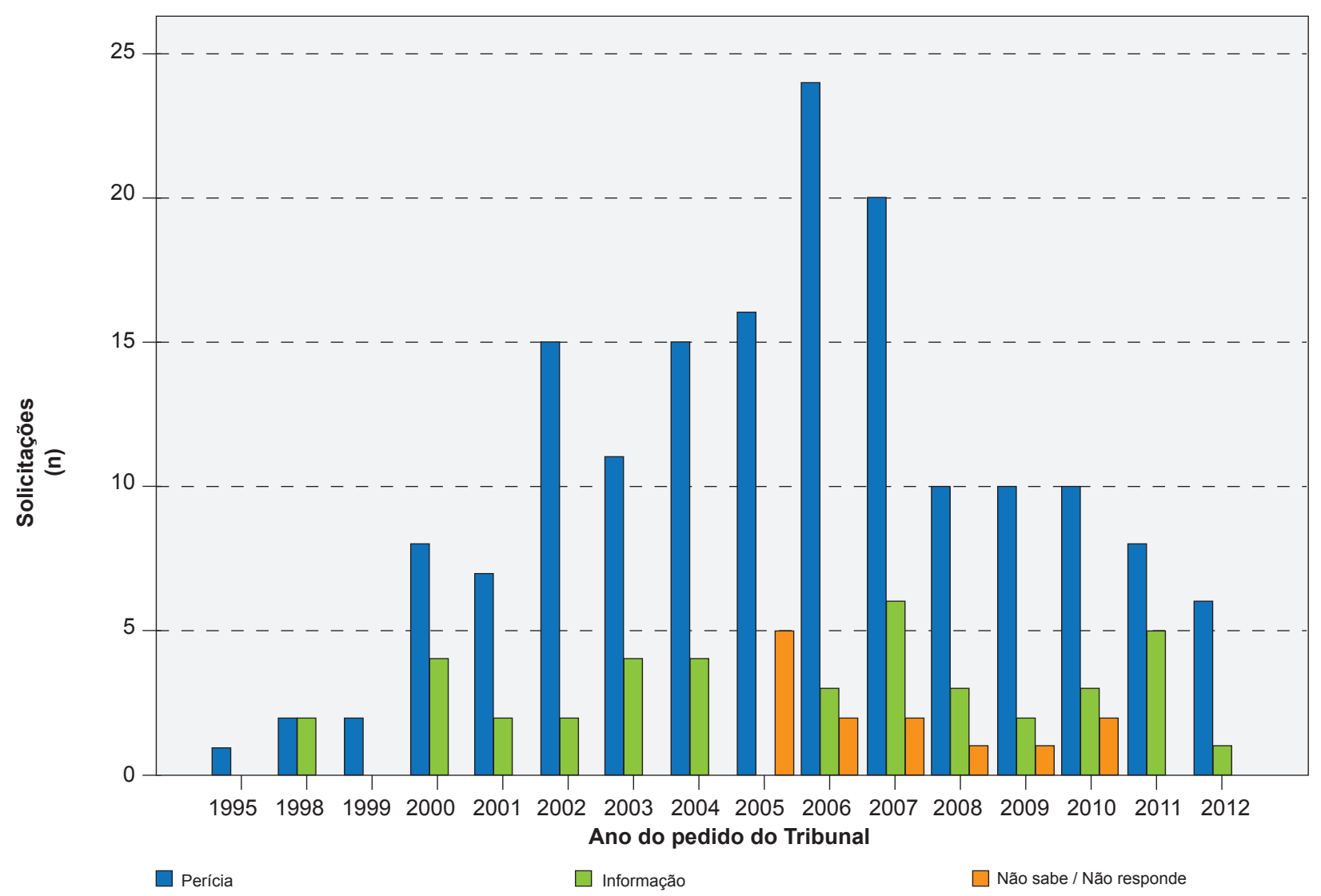

Figura 3 - Evolução do tipo de solicitações

Tabela 1 - Tempo de resposta das várias instituições envolvidas

\begin{tabular}{lcccc}
\hline Tempo de resposta & $\begin{array}{c}\text { Média } \\
\text { (dias) }\end{array}$ & Erro-padrão & Mínimo & Máximo \\
\hline Tribunal - INMLCF & 36 & 4,876 & 0 & 361 \\
INMLCF - Serviço Pedopsiquiatria CHUC & 46 & 5,699 & 0 & 298 \\
Dentro do Serviço Pedopsiquiatria CHUC & 64 & 7,648 & 0 & 395 \\
Perícia - Tribunal (1 ${ }^{\text {a }}$ entrevista até envio do relatório) & 65 & 6,503 & 0 & 617 \\
\hline
\end{tabular}


$(84,12 \%)$ não foi obtida resposta ao pedido de feedback por carta enviada posteriormente aos respetivos Tribunais. Foram ainda encontradas diversas dificuldades periciais por parte dos pedopsiquiatras em $49,5 \%$ das situações ( $\mathrm{n}$ $=114$ ).

$\mathrm{Na}$ formulação diagnóstica integrante da avaliação pericial foi utilizada a classificação diagnóstica multiaxial para crianças e adolescentes, da Classificação Internacional de Doenças, $10^{\mathrm{a}}$ edição (CID-10), ${ }^{10} \mathrm{em}$ que o eixo I corresponde ao diagnóstico psiquiátrico, o eixo II às dificuldades específicas de aprendizagem, o eixo III às dificuldades cognitivas, o eixo IV à patologia orgânica e o eixo $V$ aos fatores psicossociais (Fig. 4).

Foi possível verificar que a maioria das crianças/adolescentes avaliados não apresentava diferenças estatisticamente significativas quanto à presença ou ausência de anomalia nos vários eixos em estudo. Contudo, sobressaíram as dificuldades por fatores psicossociais, com impacto da dinâmica familiar, rede de suporte e a existência de psicopatologia parental, como observável no eixo $V(n=161)$.

\section{DISCUSSÃO}

Os resultados obtidos através da análise estatística vão ao encontro da literatura e experiência clínica relativamente aos dados demográficos e à psicopatologia. Quanto às principais dificuldades sentidas pelos pedopsiquiatras em apreço, identificam-se diversos aspetos passíveis de aperfeiçoamento, por ambas as partes, com vista a uma melhor articulação entre a Saúde e a Justiça.

Ultrapassa-nos a análise respeitante à variação no número de solicitações ao longo dos anos, parecendo-nos expectável maior solicitação de comparência do pedopsiquiatra em Tribunal no caso dos Tribunais Judiciais, por terem menor experiência na área dos menores do que os Tribunais especializados.

Um facto preponderante que sobressai é o excesso de tempo consumido, em todo o processo administrativo inerente às diferentes solicitações, para o qual contribuem diversos fatores. Constatou-se, por exemplo, que a ausência do envio das peças processuais dos Autos e os vários lapsos levam frequentemente a demoras na abertura inicial do processo. Foram vários os lapsos encontrados, nomeadamente na identificação, nas convocatórias ou no pedido de perícias sem passagem pelo INMLCF e de acordo com a área de residência dos menores.

Encontraram-se diferenças estatisticamente significativas $(p<0,001)$ entre os diferentes tempos de resposta das instituições envolvidas. Esta evidência encontra justificação num conjunto de circunstâncias, como a necessidade de se conciliar a perícia com as diversas consultas clínicas previamente agendadas, a necessidade de se realizarem várias entrevistas e das convocatórias serem mediadas pelos Tribunais, o recurso a meios complementares de diagnóstico, a discussão entre pares e por último o tempo destinado à elaboração do relatório. Também o atraso, já no decorrer das perícias, no envio das informações solicitadas relativas ao resultado das avaliações periciais psiquiátricas dos progenitores, bem como as faltas dos examinandos às convocatórias, constituem outros fatores de morosidade.

A constatação de que todo o processo burocrático inter e intrainstitucional demora, em média, mais dias que o tempo médio de realização da perícia propriamente dita, torna premente que se reduzam estes tempos, o que assume extrema relevância se tivermos em conta que o 'tempo da criança' não é o mesmo do dos adultos. A demora neste processo traduzir-se-á na manutenção de eventuais

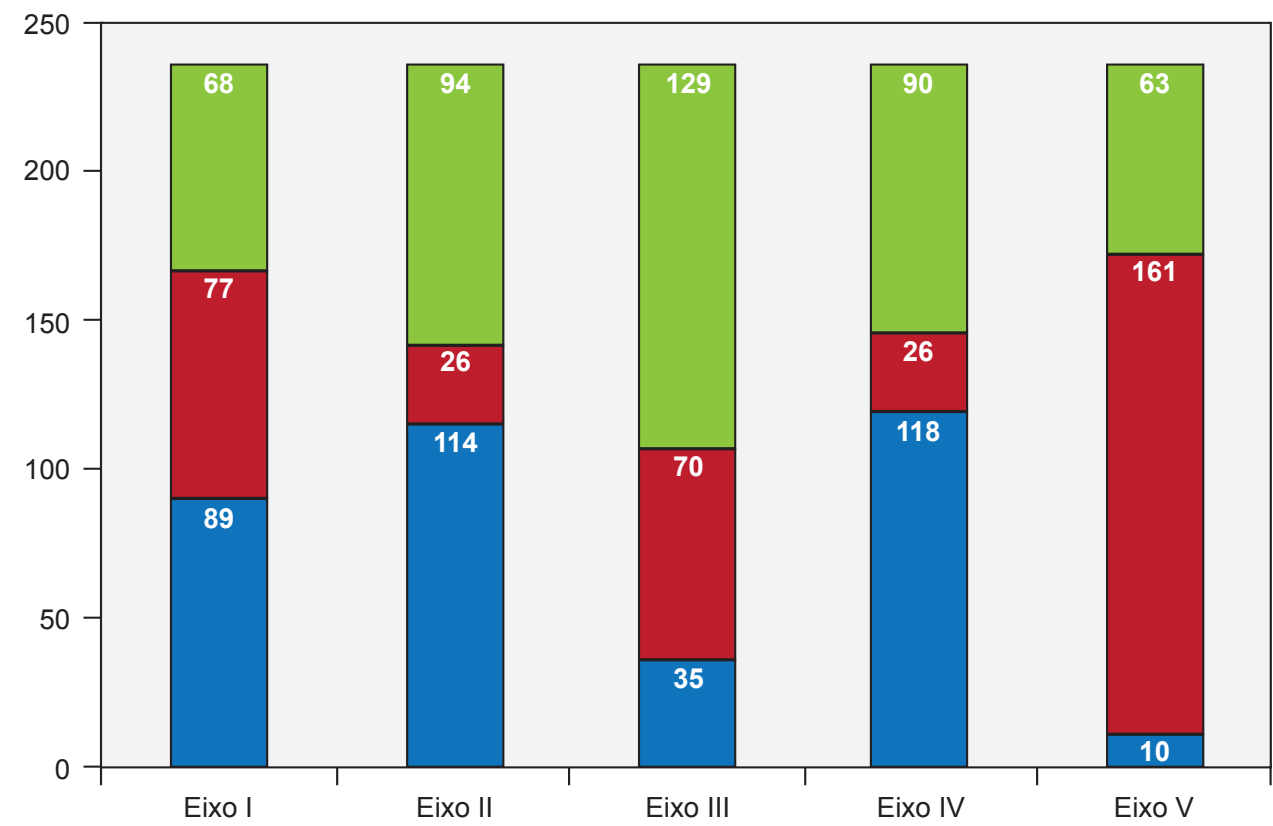

Não sabe / Não responde 
situações de risco, com todas as consequências que isso acarreta para o processo de desenvolvimento psicossocial da criança/adolescente. Situação particularmente grave em casos de maus tratos, com o risco acrescido de alteração do testemunho e em que é urgente a necessidade suprema de proteção da criança relativamente ao suposto maltratante. Caberá a todos os intervenientes nesses diferentes momentos, uma reflexão profunda acerca dos motivos para a demora, com implementação de melhores estratégias para agilizar procedimentos.

O número de entrevistas necessárias para a elaboração de relatório revelou-se consideravelmente superior perante a ausência, excesso ou inadequação dos quesitos, o que se traduz inevitavelmente numa maior demora na elaboração do relatório. Importa, neste sentido, reforçar a relevância dos quesitos e da sua otimização. No entanto, há que ter presente na formulação das questões, que a etiologia multifatorial na área da Saúde Mental não permite um mero pensamento linear causa-efeito, quando da avaliação de fatores de risco e protetores, tal como é impossível uma avaliação da veracidade dos testemunhos, como muitas vezes é solicitada.

Em $84,12 \%$ dos casos não houve resposta ao pedido de feedback feito pelos peritos às Instituições Judiciais sendo que, apesar de podermos intuir a ajuda dada pela perícia, nos impediu de efetivamente perceber se a mesma foi ao encontro das necessidades e ajudou na orientação do caso.

Foram encontradas dificuldades periciais por parte dos pedopsiquiatras em $49,5 \%$ das situações ( $n=114$ ), tais como necessidade de clarificação de quesitos, esclarecimento de lapsos ou ausência de envio de informações, algumas ultrapassáveis com um contacto mais direto entre o perito e o Tribunal.

Outros constrangimentos, apesar de não estudados estatisticamente e não contemplados nos resultados, ficam para reflexão: a existência de um agendamento pericial sobreposto à lista de espera do SNS, agravado pelas dificuldades na conciliação das agendas quando da necessidade de dois peritos, ao invés de um agendamento destinado à prática forense, dificulta não só o cumprimento dos prazos desejados, mas também a clara demarcação dos diferentes papéis do pedopsiquiatra, a falta de comparência não justificada dos examinandos às perícias agendadas, a necessidade de desmarcação de consultas de doentes urgentes para deslocações a Tribunal ou o número de horas despendidas em audiências, por vezes adiadas.

Acresce que, recorrentemente, se constata a solicitação de uma avaliação de competências parentais apenas à Psiquiatria de adultos quando, em nossa opinião, deveria ser solicitada também ao pedopsiquiatra, num trabalho de articulação, facilitado pela colocação de especialistas de ambas as áreas nos INMLCF ou em núcleos forenses nos hospitais. Efetivamente, uma avaliação deste tipo tem que ter em conta por um lado a existência ou não de psicopatologia e/ou distúrbios de personalidade dos progenitores (da competência da Psiquiatria e Psicologia Forense), mas também uma avaliação pedopsiquiátrica da criança e o estudo das interações familiares. A psicopatologia parental ou a sua ausência dificilmente permitirão por si só, inferir acerca das competências para a parentalidade. As competências parentais pressupõem uma avaliação da interação entre aqueles pais e aquela criança, cuja avaliação constitui uma competência major da área da Pedopsiquiatria, especialmente quando complementada com formação específica em Terapia Familiar.

Se em conteúdo apresentamos dados concretos e dificilmente refutáveis, já a forma e a discussão apresentadas refletirão sem dúvida a nossa visão enquanto profissionais da Saúde, com uma inerente dose de parcialidade subjacente. Seria da maior relevância conhecermos a perspetiva dos profissionais da Justiça sobre a mesma temática, bem como as suas principais dificuldades e constrangimentos.

\section{CONCLUSÃO}

Era objetivo deste estudo uma reflexão sobre o contributo da Pedopsiquiatria Forense, com vista a identificar aspetos a aperfeiçoar na articulação entre a Saúde e a Justiça e objetivar os principais constrangimentos sentidos, com recurso à análise estatística.

São, acima de tudo, as 'vidas devolvidas' a tantas crianças e adolescentes com o contributo precioso da peritagem forense, que a tornam das competências mais nobres e inestimáveis do exercício da Pedopsiquiatria.

O envolvimento pedopsiquiátrico, ao mesmo tempo que esclarece e redefine, facilitando de sobremodo o processo decisório judicial, enriquece cada interveniente pelo potencial formativo de que se reveste, nomeadamente para internos das especialidades e estagiários do Direito e da Saúde. Justifica-se, assim, a frequente e honrosa solicitação dos peritos de Psiquiatria da Infância e da Adolescência para colaboração com os Tribunais.

Indiscutível, parece-nos a necessidade de agilizarmos esta articulação entre Saúde e Justiça, visando a defesa dos menores.

Refletindo sobre este trabalho, gostariam os autores de propor algumas sugestões:

- Existência de uma via de contacto mais direta (consultadoria, e-mail, telefone) entre médico/perito e Tribunais, de modo a possibilitar o esclarecimento mais célere de eventuais dúvidas, bem como o feedback judicial;

- Colocação de quesitos simples e objetivos de forma sistemática e otimizada com vista a evitar relatórios periciais contendo informação insuficiente ou irrelevante;

- Sistematização da comunicação imediata ao Tribunal das faltas periciais e a sugestão de uma perícia em substituição do mero envio de informação, quando coloca em risco a intervenção terapêutica;

- Possibilidade de feedback, recorrendo por exemplo a formulário destacável ou o feedback por e-mail, por parte das instituições Judiciais acerca da relevância do relatório e eventuais sugestões.

- Incentivar formações pré e pós-graduadas para profissionais de saúde e direito na área do desenvolvimento 
e psicopatologia infantil na área do Direito dos Menores (divulgação de encontros científicos e mestrados comuns ao Direito e à Psiquiatria, protocolos de formação bidirecional...).

Face ao exposto e pela imprescindível motivação vocacional que deve estar implícita, afigura-se-nos da maior relevância na atualidade a implementação da subespecialidade em Pedopsiquiatria Forense, que permitiria dotar os Serviços de agendamentos reservados ao trabalho forense possibilitando uma maior e melhor capacidade de resposta.

Esperamos com este trabalho poder contribuir para um estreitar de laços nesta parceria, em prol de um mais efetivo 'superior interesse das crianças'.

\section{PROTEÇÃO DE PESSOAS E ANIMAIS}

Os autores declaram que os procedimentos seguidos

\section{REFERÊNCIAS}

1. Mesquita M, coordenação. Código de Processo Civil. $12^{\mathrm{a}}$ ed. Coimbra: Almedina; 2013.

2. Kraus LJ, Thomas CR, Bukstein OG, Walter HJ, Benson RS, Chrisman $A$, et al. Practice parameter for child and adolescent forensic evaluations. J Am Acad Child Adolesc Psychiatry. 2011;12:1299-312.

3. Ceci SJ, Bruck M. Jeopardy in the courtroom: a scientific analysis of children's testimony. Washington: American Psychological Association; 1995.

4. Agulhas R, Anciães A. Casos práticos em psicologia forense enquadramento legal e avaliação pericial. Lisboa: Edições Sílabo; 2014.

5. Walsh E. Working in the family justice system: a guide for professionals. Bristol: Family Law; 1998. estavam de acordo com os regulamentos estabelecidos pelos responsáveis da Comissão de Investigação Clínica e Ética e de acordo com a Declaração de Helsínquia da Associação Médica Mundial.

\section{CONFIDENCIALIDADE DOS DADOS}

Os autores declaram ter seguido os protocolos do seu centro de trabalho acerca da publicação de dados.

\section{CONFLITOS DE INTERESSE}

Os autores declaram não terem qualquer conflito de interesse relativamente ao presente artigo.

\section{FONTES DE FINANCIAMENTO}

Os autores declaram não ter recebido subsídios ou bolsas para a elaboração do artigo.

6. Schetky $\mathrm{DH}$. Ethical issues in forensic child and adolescent psychiatry. $\mathrm{J}$ Am Acad Child Adolesc Psychiatry. 1992;31:403-7.

7. Ordem dos Médicos. Regulamento n¹4/2009: Código Deontológico da Ordem dos Médicos. Diário da República $n^{\circ} 8$, II Série, de 11 de Janeiro de 2009.

8. Black D, Harris-Hendriks J, Wolkind S, editors. Child psychiatry and the law. $3^{\text {rd }}$ ed. London: Gaskell; 1998.

9. Godoy R. A responsabilidade civil no atendimento médico e hospitalar. Rev Tribunais. 2000;89:87-116.

10. World Health Organization. The ICD-10 Classification of Mental and Behavioural Disorders: Clinical Descriptions and Diagnostic Guidelines. Geneva: WHO; 1993. 